\title{
Enhancing tourism education: The contribution of humanistic management
}

\author{
Maria Della Lucia ${ }^{1}$ (D) Frédéric Dimanche ${ }^{2}$. Ernestina Giudici ${ }^{3}$. \\ Blanca Alejandra Camargo ${ }^{4} \cdot$ Anke Winchenbach $^{5}$
}

Received: 9 July 2021 / Accepted: 11 November 2021 / Published online: 2 December 2021 (c) The Author(s), under exclusive licence to Springer Nature Switzerland AG 2021

\begin{abstract}
The tourism industry is a significant driver of the global economy and impacts societies all over the world that are currently experiencing radical change. Responding to these changes requires economic paradigms and educational systems based on new foundations. Humanistic tourism proposes a values-based disciplinary perspective for tourism at the intersection between humanistic and tourism management, and is rooted in human dignity and societal wellbeing. Integrating humanistic management principles into higher education tourism management programs, and changing the nature of what is taught and how, would benefit students, future managers and all stakeholders. This paper aims at improving higher education tourism programs by combining humanistic management education and the Tourism Education Futures Initiative's (TEFI) values-based tourism education. It draws on an integrated Humanistic Tourism Education framework to help develop future tourism managers' skills and abilities to adopt alternative leadership models within the sector and to foster critical and responsible tourism thinking and practice. With best-practice examples from three universities in three different countries, this study illustrates new pedagogical approaches and proposes recommendations for implementing humanistic tourism management in higher education with the aim of training ethical and responsible managers equipped with an awareness of the social, cultural, and environmental challenges - and possible solutions to these - in their respective destinations.
\end{abstract}

Keywords Tourism · Humanistic management $\cdot$ Values-based education · Dignity · Humanistic tourism education

\section{Introduction}

Humanistic tourism offers a new disciplinary perspective rooted in the interdependent relationship between humanistic and tourism management. It leverages human dignity, meaningful work, the ethical dimensions of working, and the promotion of well-being (Pirson 2017) to highlight and overcome the weaknesses of current management approaches and

Maria Della Lucia

maria.dellalucia@unitn.it

Extended author information available on the last page of the article 
equip researchers and practitioners with concepts, tools, and strategies to deal with the current challenges and crises tourism faces. In the wake of global challenges, including climate change, pandemics, and the need for social responsibility and sustainability, this interdependent relationship is relevant and urgent from both a theoretical and a managerial perspective (Della Lucia and Giudici 2021a).

Tourism education should complement the new theoretical and managerial perspectives that address a world in transition, as knowledge (co-)creation through innovative teachinglearning processes drives evolving streams of research, practice, and behavior at different levels (Pirson et al. 2019). Tourism education needs to be redesigned, by changing the nature of what is taught and how, to build the capacity to lead the industry into a sustainable future (Sheldon et al. 2008). This redesign could greatly benefit from the integration of humanistic management principles in tourism education and management (Della Lucia and Giudici 2021a). The values-based perspective of humanistic management is crucial to shed light on the ethical and sustainability-related issues that the paradoxes and crises of the tourism industry have laid bare in both developed and developing countries (Della Lucia and Giudici 2021b) and to repair the damaged social contract between business and society by putting human dignity at the heart of the industry and its management (Swanson 2004 p. 57).

Universities as sources of innovative thinking and change at the highest level must play a crucial role in building the capacity of tourism students (and future managers) to lead an industry facing increasing pressures to become responsible stewards, now and in the future (Giudici et al. 2020). Furthermore, current, and future managers and entrepreneurs have to adopt values-based leadership models that will pave the way towards business practices that ultimately serve human ends and respect human dignity (Santonino 2021).

Sustainability and (corporate) social responsibility are increasingly part of the tourism programs (Boyle et al. 2015) offered by universities, local institutions, and corporations. Yet, despite the acknowledged need to build (back) a better form of tourism (UNWTO 2020), there is currently a gap in the awareness, understanding, development, and implementation of humanistic management as part of tourism curricula amongst educators and practitioners which, if addressed, could instigate and support such change (Della Lucia and Giudici 2021b). The Tourism Education Futures Initiative (TEFI)'s framework for reshaping the tourism curriculum (Sheldon et al. 2008) allows space for the full integration of humanistic management into tourism education. In the post-pandemic world, this integration seems even more promising as society is readier to question and rectify many of the ways of knowing, doing, and being within tourism that are now revealed as problematic.

This paper aims to enrich and improve higher tourism education by leveraging humanistic management (Melé 2016) to build the capacity for future generations of tourism managers, leaders, and other stakeholders to adopt alternative models and practices based on the re-discovery of what it means to be human and what matters most to humanity. Building on the recent literature on humanistic tourism (Della Lucia and Giudici 2021a), humanistic management and sustainable tourism (Della Lucia and Giudici 2021b), and advances in tourism education (Sheldon et al. 2008), we integrate humanistic management education (Pirson and Amann 2010) into the new paradigm for values-based tourism education (TEFI 2010). This integrated framework is applied to analyze illustrative case studies by adopting constructive alignment (Biggs and Tang 2015), a curriculum design system for high-level learning that identifies the intended learning outcomes (ILOs) and the teaching methods and activities (most) likely to lead to them. Our methodological approach in applying constructive alignment is guided by Brookfield's (1987) critical thinking. The selected case studies include education programs/courses offered by third-level institutions (universities), 
focusing on tourism management, and involving teachers familiar with humanistic management. Preliminary pedagogical strategies are developed from case study analyses with the aim of contributing to the debate on tourism education and, ultimately, innovating, and inspiring education programs and business practice.

\section{Humanistic tourism: The application of humanistic management to tourism}

All systems change over time (Burnes 2005), and the world is experiencing radical transformations. External shocks have shaken our economies and societies, exposing their fragility, and highlighting the need to be able to act, think, and plan differently in, and adjust to the impacts of, complex scenarios (Sheldon et al. 2008). Humanistic management has grown out of a recent strand of studies that draw together the concepts of social business, sustainability, social entrepreneurship, business ethics, conscious capitalism, and cooperative capitalism to present a new humanism-based research paradigm (Melé 2016; Pirson 2017). This paradigm addresses global economic and social crises, including pandemics, by challenging the prevailing neo-liberal economic paradigm that dominated twentieth-century management theory and practice. The paradoxes and tensions of capitalism, and the weaknesses of this uneven system, have been dramatically revealed, highlighting the need to move towards new development and business models based on different foundations.

Humanistic management seeks to change the current economic paradigm by moving from "mechanistic management" to the humanizing of business and to humanism in economies and societies (Melé 2016). The humanizing of business (Pirson and Turnbull 2011) is founded on the promotion of the unconditional human dignity of every human being (Spitzeck 2011) and the development of human virtue, in all its forms, to its fullest extent (Melé 2003). By putting human beings at the center and leveraging dignity, justice, and equity to promote fair practices in employment and value creation, humanistic management becomes an enabler of share-value generation processes aimed at the well-being of society and sustainability (Pirson et al. 2019). The protection of human dignity and the development of people's capabilities (Nussbaum 2011) allow us to transform unequal systems by appealing to principles of morality, justice, equality, and autonomy.

Humanistic management has become a promising area of research, practice, policy, teaching, and education across all sectors as an alternative business and development approach. The tourism industry offers significant opportunities for the practical application of humanistic management as it is a driver of economic development in both developed and developing countries, despite its inherent paradoxes, vulnerabilities and crises: for all its economic and personal development benefits, tourism is also responsible for welldocumented social, environmental, and economic problems (Gössling and Hall 2006). A significant contributor to pollution and climate change through its heavy reliance on air travel (Becken 2013), tourism is also criticized for its growth and profit-making logic, and its inequitable and exploitative labor practices (Bianchi and de Man 2021). Precarity, poor career prospects, low salaries, imbalances between professional and family life, prejudice and discrimination, a lack of mechanisms of inclusion, deficient equality, are among the problems in urgent need of solution (Winchenbach et al. 2019). In recent decades, moreover, the sector has demonstrated its alarming susceptibility to international crises, from terrorist attacks to pandemics. COVID-19, the latest shock, led to 62 million job losses in 2020, and the contribution of travel and tourism to world GDP dropped from $10.4 \%$ in 
2019 to $5.5 \%$ in 2020 , with a $\$ 4.5$ trillion GDP loss (down $49.1 \%$ in one year), according to the World Travel and Tourism Council (2021). Crises hurt front line workers most: in developed countries these are often women and racialized immigrant people (Wright and Dimanche 2021). Tourism, as a labor intensive industry present in all countries, is probably more vulnerable than other sectors to crisis, whether economic, social, or environmental (Calgaro et al. 2013; Espiner and Becken 2014).

The industry's weaknesses have led to a number of calls for a rethink of what tourism should be (Dwyer 2016; Higgins-Desbiolles et al. 2019). The adoption of a humanistic management perspective is likely to prove a promising avenue towards achieving more sustainable and ethical forms of tourism, and guiding managerial practices toward equity, justice, and fairer outcomes for the individuals and groups that have been affected by unplanned and unjust tourism development and management. Humanistic tourism (Della Lucia and Giudici 2021a) is a recent notion, positioned at the nexus between humanistic and tourism management, which has established a values-based disciplinary perspective on tourism. Because tourism is an information-intensive industry and an "experience good" resulting from the relationship and co-creation processes involving hosts and guests in different political, socio-economic, cultural, ethnic, and environmental contexts, humanistic tourism interlinks micro, meso, and macro levels of interest and application (Gretzel et al. 2006).

Humanistic tourism is a business and development model based on sharing and implementing humanistic management principles aimed at exposing and transforming uneven systems and creating economic, human, social, and environmental value (Della Lucia and Giudici 2021b). On the one hand, it challenges established perspectives in tourism management, highlighting their inadequacies (mainly inherited from economics, human resource management, and efficiency-driven management). The prioritization of economic goals by governments and the private tourism sector - leading to an excessive focus on tourism arrivals, tourism receipts, efficiency, costs, profit, etc. - has meant that tourism is fueling capitalism (Fletcher 2011) thus exacerbating circumstances of injustice, unfairness, and inequality (Cole and Morgan 2010). These circumstances include the systemic displacement of local people from their ancestral lands (Mbaiwa 2016), labor exploitation (Redwood 2008), discrimination and exclusion in public spaces (Manuel-Navarrete and Redclift 2012; Steele 2012), and marginalization in tourism decision-making processes (Camargo 2011), all of which affect people's dignity, livelihoods, and well-being. On the other hand, humanistic tourism speaks directly of human dignity and values, thus explaining, analyzing, and interpreting the importance of topics that have to date been largely ignored (Della Lucia et al. 2021b). Closely bound up with justice, equality, and autonomy, recognizing and respecting individual value (i.e., dignity) involves different value creation processes in the interests of organizational and social progress (Camargo and Jamal 2022). These processes entail recognizing people's will, consent, and capacity, enabling their active participation in decision-making processes to obtain fair (and sustainable) outcomes (Camargo and Vazquez-Maguirre 2021). They allow people to benefit from basic resources and societal goods, participate in their own personal growth and fulfillment, and interconnect with the environment and all living beings (Melé 2016). Installing a values-based and humanistic set of norms not only fosters prosperity and human flourishing but also reduces inequalities (Higgins-Desbiolles 2006) and enables morality under circumstances of injustice or unfairness (Waldron 2013) as the duty to safeguard dignity is made paramount.

The COVID-19 pandemic has prompted discussions around the future of tourism (Brouder 2020; Dubois and Dimanche 2021; Gössling et al. 2020; Hockings et al. 2020). The scenarios range from tourism as usual (the "old normal"), to tourism as un-usual (the 
"new normal") and to a reboot of the industry. Humanistic tourism fits within the more optimistic scenarios and is part of a multidisciplinary approach to a root and branch transformation of tourism (Niewiadomski 2020).

Humanistic tourism must be in line with regenerative economics (Ateljevic 2020; Jamal 2021): being in an appropriate relationship with both the culture and the ecosphere in which the human economy is embedded; viewing wealth holistically in terms of the well-being of the 'whole' instead of mere money; being creative, innovative, adaptive and responsive; empowering participation of individuals and groups; honoring and nurturing healthy and resilient communities and places; cultivating diversity as a source of creativity; shaping circulatory, and value-enhancing flows (of information, production, etc.); and seeking a balance between dichotomies.

The humanistic tourism perspective constitutes a response to climate change and favors the transition to a carbon-neutral economy by "flattening the (growth) curve" (Prideaux et al. 2020). It is an approach that readily aligns with the circular economy model, making use of old and new strategies favored by technology-driven innovation. As is well known, the model entails reducing, reusing, and recycling, temporarily accessing underutilized physical assets rather than owning or buying new ones, and moving from inbuilt obsolescence to repair and reuse for other purposes.

The humanistic approach reappropriates the connotation of tourism as a social force (Higgins-Desbiolles 2006, 2020) which acts to connect human beings, fostering dialogue between local communities and tourists, empowering, and building greater well-being for locals, not disregarding broad social promises, including justice, equity, and autonomy. In this vein, humanistic tourism embodies tourism as "Buen Vivir" (Everingham and Chassagne 2020). It moves towards small-scale, slow, local forms of tourism that can create greater social and environmental wellbeing, and meaningful human connections.

Multidisciplinary thinking about a new tourism configuration converges around a significant change in how humanity perceives our planet, our relationships with nature, with each other, and with technology. The humanistic tourism model thus entails four avenues for change - human vs. human, human vs. nature, human vs. technology, and human vs. the economy - which represent possible alternatives not only for tourism but for managing businesses and fostering a better economy (Della Lucia et al. 2021).

\section{Tourism Education: The Tourism Education Futures Initiative (TEFI)'s framework}

The increasing pressure to act as a responsible steward that tourism faces led to the Tourism Education Futures Initiative (http://tourismeducationfutures.org/), a series of summits originally sponsored by five universities (Temple University and University of Hawaii, USA; The University of Queensland, Australia; Bocconi University, Italy; and Modul University, Austria) which drew up recommendations to adapt tourism education to societal and industry change between 2010 and 2030 (Sheldon et al. 2008).

TEFI's framework is a values-based tourism education program that identifies the values, knowledge, and capabilities needed to lead tourism into the future positively, responsibly, and effectively. Ethics, knowledge, stewardship, professionalism, and mutuality are the five interconnected values-based principles that should govern the development of the tourism world and that the tourism education program should embody to train responsible leaders (Fig. 1) (TEFI 2010). These principles are interconnected and show permeability; 


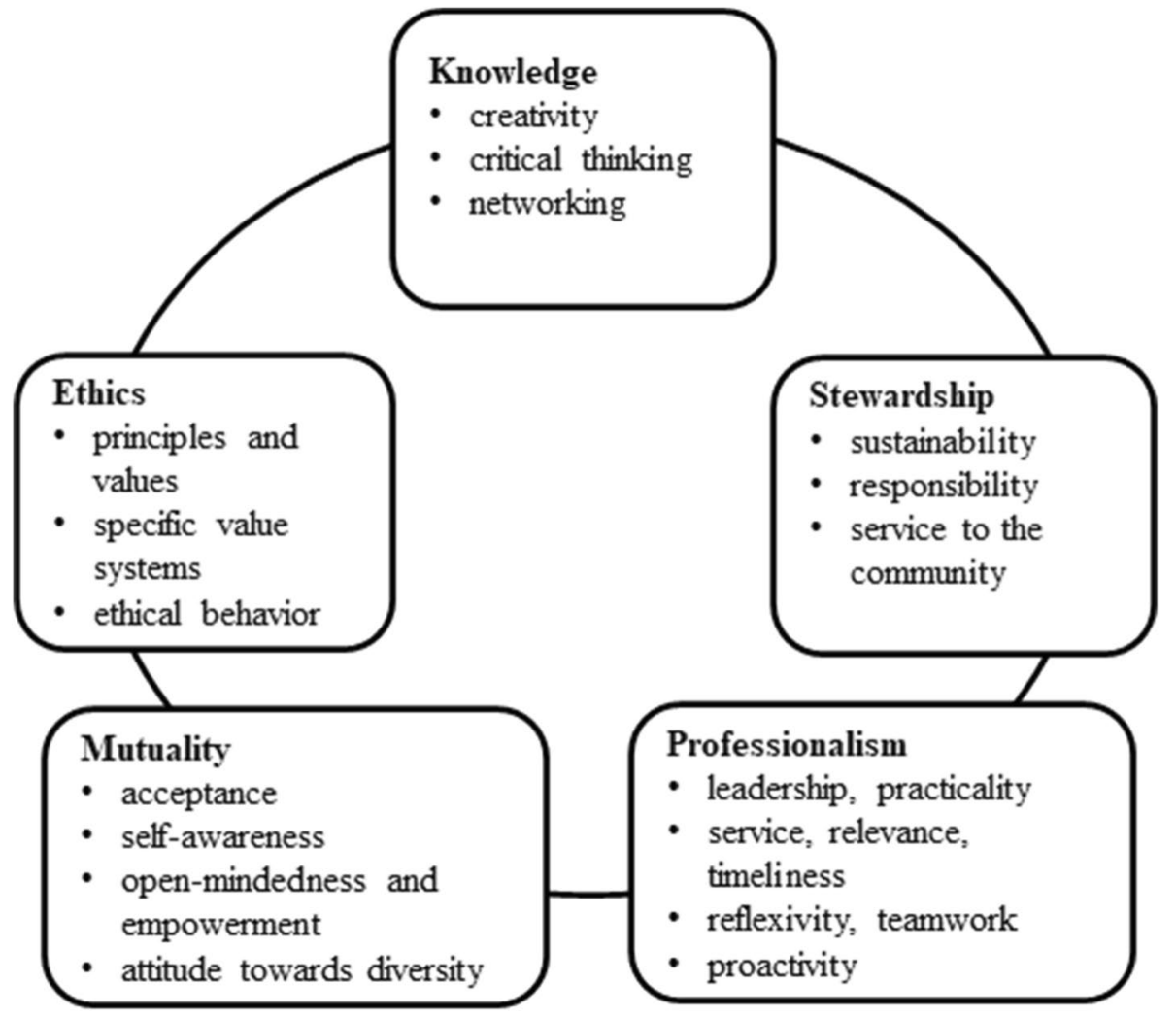

Fig. 1 TEFI values

each includes a set of content that should be incorporated into the learning experience, and which may be expanded over time.

Ethics is the system of principles and values that allows us to distinguish, and judge, good or questionable actions. Different value systems have different ethical traditions and principles, which require understanding and respect. Knowledge encompasses creativity (the generation of new ideas, approaches, actions), critical thinking (being critical of the constitution of knowledge and underlying dogmas), and networking (social environments) - all needed for change and innovation. Stewardship entails a duty of care and the acknowledgement of assuming responsibility. The value of stewardship translates into sustainability, responsibility, and service to the community on the one hand and, on the other, into the power and leadership related to the governance aspect of stewardship. Professionalism includes leadership, a practical approach (practicality), attention to service, concern for the relevance and timeliness of evidence, reflexivity, teamwork and partnership building skills, and proactivity. Finally, mutual respect is a value grounded in human relationships that requires an evolving, dynamic attitude and involves acceptance, self-awareness of structural inequalities, open-mindedness, empowerment, and the ability to revisit one's cultural understanding of the world. Achieving mutual respect may well be a life-long learning process; it can be developed at different levels, starting from the individual (understanding self-identity) and expanding to the societal and global. The exposition, understanding, and 
acceptance of diverse social and cultural values, behaviors, and positive attitudes towards diversity encourages the development of mutual respect. The incorporation of these values-based principles into tourism education programs allows us to build the skills that students need to master: destination stewardship skills, political skills, ethical skills, enhanced human resource skills, and dynamic business skills (Sheldon et al. 2008).

\section{Moving forward: The Humanistic Tourism Education framework}

This contribution enriches higher education in tourism by combining humanistic management education (Pirson and Amann 2010) and TEFI's values-based tourism education framework (Sheldon et al. 2008) to create an integrated framework (Fig. 2) intended to provide future responsible managers with the skills and abilities to adopt alternative leadership models within the sector. This integration is based on the convergence between the premises of humanistic management and the main challenges that TEFI is endeavoring to address through its reshaping of tourism education: the need for corporate and broader societal values to tackle the prevailing neo-liberal economic paradigm and its related tensions, paradoxes, and crises at different levels (micro, meso, and macro). University business schools have been fiercely criticized for their failure to give

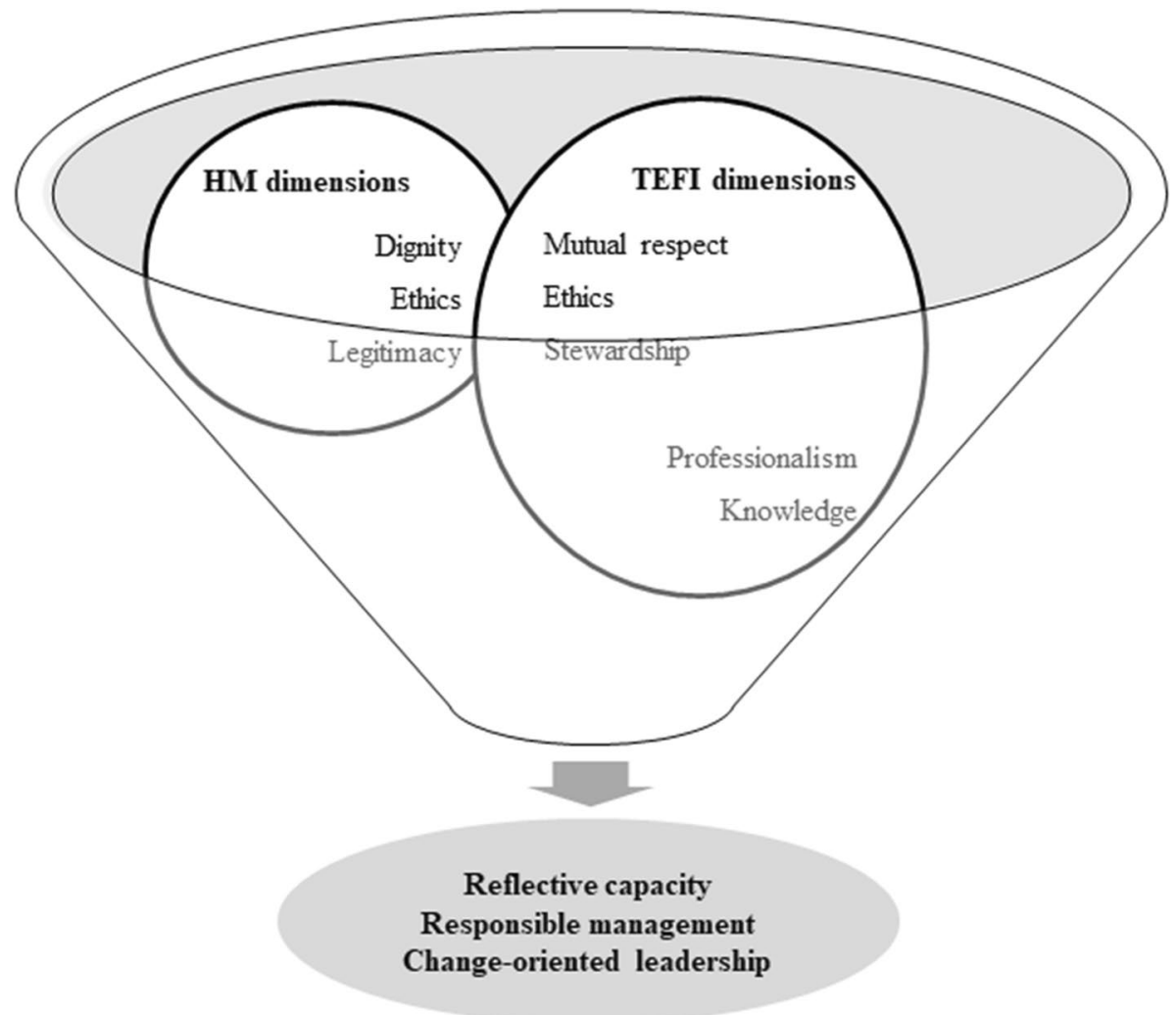

Fig. 2 The humanistic tourism education framework 
adequate attention or leadership to this part of the curriculum for future business leaders (TEFI 2010): such academic leadership is essential to prepare people to become critical thinkers and humanistic managers. As Tribe (2008 p. 254) suggested, "if tourism does not become a fully critical business, it will seek only technical solutions to issues of management and governance."

The humanistic tourism education framework is conceptualized as a combination of TEFI and humanistic management, it entails expanding TEFI with the overlapping values between TEFI and humanistic management, letting some of the TEFI values be preserved. The ethics, stewardship, and mutuality required of a tourism education program are closely mirrored in the dignity, ethics, and legitimacy key to humanistic management. Within humanistic management, unconditional respect for the dignity of every person (individual respect) is the foundation for interpersonal interactions - both within and outside business contexts - grounded in mutuality or mutual respect. Ethics (behavior and evaluation) is also integrated into all business decisions and is the foundation for responsibility. Normative legitimacy for corporate activities (leadership and shared governance models) is crucial for the assumption and sharing of responsibility at the systemic, organizational, and individual levels (stewardship). The combination of these three dimensions (dignity, ethics, and legitimacy) connects self-respect and morality to mutual respect and corporate responsibility for systemic consequences (sustainability), attempting to promote human flourishing, adding value to society at large, and helping to alleviate social problems through business and economic activities such as tourism (Lieberman and Havens 2002).

The humanistically oriented reframing of these overlapping values explicitly connects elements of humanistic management to the values upon which a new approach to business and management education in the tourism field is based (Pirson 2017; Pirson and Amann 2010) and builds the skills and abilities required to adopt effective alternative models that can lead tourism successfully into the future. The overlap between TEFI's values-based principles and humanistic management is manifest in the affinity between the capacities that the two approaches aim to foster (Pirson and Amann 2010; Sheldon et al. 2008) and enables them to coalesce into the integrated outcome of the humanistic management education framework (Fig. 2). Future responsible managers are trained to build reflective capacities such as critical thinking by providing them with the relevant knowledge and information in order to foster change-oriented leadership. By strengthening their reflective functioning, we enable them to better understand the context in which they will be acting - the society, political environment, economy, institutions (and these entities' moral legitimacy) (political and ethical skills). Equipping them with the relevant knowledge and information, and combining practice and theory in an integrated manner, allows them to build the skills required to manage responsibly (stewardship skills). Building students' capacity to become agents for positive societal change requires their involvement in surrounding communities and engagement with the challenges that these communities face; such involvement may entail service-learning, internships in social enterprises, or immersion programs aimed at creating solutions to local and global problems and/or personal development (dynamic business skills and enhanced human resource skills). Problem-based or activity-based learning methods use real-world problems as contexts in which students can develop their critical thinking and problem-solving skills, as well as acquiring course-related knowledge. Being immersed in a third place (outside the classroom) confronts students with reality and creates powerful and memorable learning experiences that call upon their five senses and can transform the individuals involved and how they see the world. 


\section{Three illustrative case studies: Humanistic Tourism Education in practice}

The Humanistic Tourism Education framework is used here to analyze and discuss a selection of education courses/seminars (Yin 2014) that were offered in three universities in Mexico, Canada, and Italy, focused on tourism management, and involving teachers familiar with humanistic management. They include: the Seminar of Tourism and Hospitality within the International Tourism Program at the Universidad de Monterrey, Mexico; the Field Studies in Hospitality and Tourism course at Ryerson University, Canada; and the Economy of Culture and Tourism course within the MA program in Linguistic Mediation, Tourism and Culture at the University of Trento, Italy.

Case study presentation and analysis is carried out using constructive alignment (Biggs and Tang 2015), an outcomes-based teaching and learning approach which elaborates the 3Ps model (presage-process-product) of Dunkin and Biddle (1974) and conceptualizes learning processes and outcomes as the result of the relationships between students' characteristics and inputs, on the one hand, and the overall teaching and learning context, on the other. In this curriculum design system for high-level learning, students construct learning through active and multifaceted processes. Teachers align the teaching system by defining the intended learning outcomes (ILOs) that students must achieve (the topics and levels of understanding in each topic are defined according to Bloom's Taxonomy), choosing both the teaching methods and activities likely to lead to the intended ILOs and the most appropriate tasks for assessing student progress. Constructive alignment is critically applied (Brookfield 1987) by trying to understand and reflect on ideas from multiple fresh perspectives that challenge existing assumptions and then exploring appropriate actions; this method stands at the heart of pedagogy and practice in tourism higher education (Jamal 2004; Slocum et al. 2019; Tribe 2002). Tourism education will benefit more from the critical application of constructive alignment once humanistic management integration has been widely implemented.

\section{The Tourism and Hospitality Seminar, Universidad de Monterrey, Mexico}

The Tourism and Hospitality Seminar is an advanced course on the Bachelor of Science Program in International Tourism at the Universidad de Monterrey. It includes discussion of selected topics and scenarios affecting tourism and hospitality planning, management, and marketing: climate change, ethical decision-making, future tourism scenarios, and tourism models for well-being. The Humanistic Management module was introduced in the Spring of 2021 with the aim of raising students' awareness of tourism's impact on individual and collective dignity and well-being and developing managerial competencies to make decisions and implement strategies that elevate human dignity, foster flourishing, and improve societal well-being; it can also be integrated into graduate tourism courses. The intended learning outcomes were:

- Understanding the principles of Humanistic Management and Humanistic Tourism

- Articulating the concept of dignity and its psychological, cultural, economic, and labor dimensions 
- Recognizing tourism and hospitality planning, management and marketing practices that violate people's dignity and well-being

- Analyzing secondary data to assess the working conditions and well-being of people involved in the hospitality and tourism industry

- Proposing managerial practices that protect people's dignity and promote their wellbeing in tourism and hospitality organizations and destinations

In pursuit of these outcomes, the teaching activities were organized in four sessions. The first two provided the theoretical foundations of humanistic management, humanistic tourism, and its relationship to other forms of tourism, offered a solid understanding of dignity and its spheres, and promoted critical reflection about the ways in which tourism practices can harm or support people's dignity and well-being. Teaching methods included selected readings, reflective thinking using a selection of case studies (sometimes working in groups or through in-class discussions) to analyze tourism's impact on the dignity of individuals, women, and indigenous groups.

Sessions three and four required students to apply the relevant theoretical concepts to real-life tourism and hospitality scenarios, with the intention of empowering students to propose managerial practices that protect people's dignity and promote human well-being and to recognize/experience tourism companies that are having a positive impact in their destinations and on stakeholder groups through ethical practices, social responsibility, meaningful work, or dignity-related practices, among others. Activities included reflective thinking on humanistic destination management and marketing and employment practices. For example, students used the American Marketing Association Code of Conduct (https:// www.ama.org/codes-of-conduct/) to imagine a tourism marketing campaign that respected and empowered local people, including women, and to consider how to balance the needs of the tourism industry with those of the local people, their culture and their environment. Students worked in groups to conduct secondary data research to assess the labor conditions of hospitality and tourism workers in a chosen destination or to develop a qualitative survey to explore issues in the workplace as experienced by a group of tourism employees, and then to propose changes to current tourism employment policies and practices. Future activities could include field visits to local hospitality and tourism enterprises, guest speakers from selected tourism organizations, group presentations of examples of hospitality and tourism organizations or of projects that are having a positive impact in local communities.

\section{The Field Studies in Hospitality and Tourism course, Ryerson University, Canada}

The Field Studies in Hospitality and Tourism course at Ryerson University was created in 2016 to give Bachelor of Commerce students a first-hand immersive travel experience and an understanding of how hospitality and tourism professionals address strategic and community-based tourism issues in a real-world context. In the past few years, three different professors have taken students to Cuba, Jamaica, and to indigenous communities beyond the Arctic circle in the Northwest Territories of Canada. Open to students who already have a first degree, this course aims at (1) understanding the complexities of developing community-based tourism, (2) contrasting the dynamics of community-based tourism with those of traditional mass tourism development, and (3) developing an appreciation of the pillars of humanistic management in the context of community-based tourism. The 
discussion below specifically applies to the course that took place in Jamaica, taught by one of the article's co-authors.

Jamaica is known as a popular Caribbean destination that became successful at mass enclave-tourism. Tourism enclaves can be defined as "all-inclusive" resorts where tourists are welcome, but locals are segregated and excluded (McFarlane-Morris 2021), reflecting a type of tourism associated with neo-colonialism. Next to those resorts, locals are attempting to develop smaller-scale tourism enterprises that would better benefit the population at large. This island destination context presents a unique case to help students understand the development forces at work in the planning and development of tourism on islands (Dodds et al. 2018) and the contrasting modi operandi and values of mass tourism and communitybased tourism.

The intended learning outcomes included:

- Learning first-hand about the destination's strategic development orientations, their challenges, successes, and management and policy implications.

- Understanding and contrasting the drivers for and the challenges to community-based tourism development with a concern for sustainability principles, in comparison with enclave tourism.

- Understanding the consequences of various management and marketing strategies in the destination.

- Evaluating from first-hand experiences the different forms of tourism present (e.g., voluntourism, mass tourism, ecotourism, resort tourism, adventure tourism) with a focus on community-based tourism

- Developing social and communication skills in an international context

To achieve the above outcomes, the course consisted of an experiential-learning 10-day trip to Jamaica. Co-designed with a local voluntourism tour operator, the trip followed an itinerary around the island that was punctuated with visits to both all-inclusive resorts and hotels and national parks, cultural and historical attractions, farms and coffee plantations, eco-resorts, restaurants, and arts and crafts producers and distributors. The visits provided opportunities to meet and engage with managers or entrepreneurs, community leaders, university lecturers, and public servants. Students stayed in a variety of places, from huts in a Rastafari village, to homestays with families, or camping in the Blue Mountain National Park. They were also involved in a community outreach volunteer project where they assisted homeless people in a town, delivering health and hygiene packages.

Students had the opportunity to engage with all kinds of tourism stakeholders, from the director of Jamaica Tourism at the Ministry of Tourism in Kingston to community leaders in small villages. Pre-trip readings gave the students the necessary background information on the Jamaican context and community-based tourism. Discussions with the various stakeholders were focused on understanding and contrasting the country's Janus-faced tourism: on the one hand, glitzy and expensive all-inclusive resorts, and on the other, underdeveloped tourism infrastructure in poor districts, with struggling community entrepreneurs, despite the richness of the natural and cultural heritage. The conversations took place in colonial farms, in schools, office buildings, or during walks in natural settings. Each day ended with a reflective group discussion to address the questions and issues that had arisen during the day's visits and activities. These group discussions were moderated and given added context by the Jamaican tour operator and guide.

Among the assignments, students had to draw concept maps of Jamaican tourism reflecting various modes of development; they were asked to make recommendations for 
a national community-based tourism development strategy, and they had to write a selfreflective piece about their experiential learning trip. This field study course provides a unique opportunity for students to explore the values-based principles associated with humanistic management and gives them a foundation that will set them apart as future tourism leaders and agents of change, as this testimony suggests (Lo 2018).

\section{The Economy of Culture and Tourism course, University of Trento, Italy}

The Economy of Culture and Tourism course is included in the MA program in Linguistic Mediation, Tourism and Culture at the Department of Humanities of the University of Trento, a multi-disciplinary program developed in collaboration with the university's Department of Economics and Management. It is the only Tourism Planning and Management MA program of its kind in Italy, developing cross-competences in tourism and cultural management, foreign languages (including Chinese and Russian), and cultural mediation.

The course aims to increase students' understanding of, and capacity to analyze, culture as a driver of sustainable development, inclusion, and innovation in post-industrial societies. Culture-based regeneration is an important manifestation of these processes. Tourism is also involved, as it capitalizes on heritage and creativity to contribute to both community development and well-being (in terms of employment, inclusion, social innovation) and the strengthening of social capital: all changes that simultaneously meet social needs and improve individuals' skills, relationships, and capacities to act. The multifaceted nature of culture - ranging from material and immaterial traditional cultural heritage (cultural core) to the cultural industries (film, publishing, music), creative industries (fashion, design) and related industries (Information and Communication Technologies or ICT) - and the many intersections between it and tourism makes it a highly appropriate vehicle for fostering sustainable development, inclusion, and innovation. Cross-fertilization between the cultural and creative industries and tourism assumes different forms, such as creative and relational tourism and humanistic tourism, which require an understanding of the values-based principles associated with tourism.

The intended learning outcomes include:

- Understanding the principles of sustainable development and the role of culture and tourism in driving (sustainable) development, wellbeing, and inclusion

- Articulating the notions of culture and cultural and creative industries and their connections to human and social dimensions

- Recognizing forms of culture-led development and its cross-fertilization with tourism

- Recognizing and developing forms of humanistic tourism through acknowledgement of the value of people, communities, places, and local heritage and enhancing their value

- Proposing managerial practices and tools to foster culture-led regeneration that combines tradition (identity) and innovation, thus allowing places/communities to remain faithful to their sense of place while enhancing opportunities for generating value

- Increasing students' ability to innovate, network, and participate creatively 
To achieve the outcomes, theoretical frameworks are provided, complementary readings are suggested, and several case studies are discussed in the classroom using a participative approach. Students also work in small groups, identifying cases of interest (newspapers, blogs, etc.), interpreting these cases through the frameworks provided, and then presenting and discussing them in the (virtual) classroom.

Over the years, innovative participative education formats (including experiential labs, workshops, and stakeholder dialogues) have also been experimented with to provide students with immersive learning experiences allowing for the application of ideas, frameworks and concepts to real life, stimulating students' reflective thinking and integration of knowledge and expertise. These education formats involved actors, storytellers, writers, and practitioners from the cultural and creative industries and tourism. They drew on diverse sources of knowledge/expertise and methods of communication to develop engaging teaching, education, and training activities. Local institutions and enterprises were also involved in the organization of these events, hosting them in places closely linked to the event themes.

Some examples of the activities developed follow. "ReGeneration: WomenInCulture" was a series of events involving women professionals in the cultural and creative industries who are agents for positive change in culture and tourism management. The ways in which they approach, develop, and communicate their creative work can be located at the intersection of different processes of change, stimulating reflective thinking around these processes in different contexts and with different languages and experiences. These processes of change include multiple drivers. First, the creative class who are agents of change and innovation - i.e. women in creative professions impact the economy, society and culture. Second, culture (cultural and creative industries) which can lead to the positive transformation of territories, businesses/organizations, communities and people. Third, crises (such as the current COVID-19 pandemic), which can provide opportunities for reinterpretation, rethinking, and transformation, and might even lead to a new Renaissance. The women professionals (an international project manager in a digital innovation company, a writer and photographer, a museum director, and a storyteller) gave interactive speeches developed from six keywords and actions that had inspired them to become agents of change in their lives, careers (and crises).

"Dialogue on culture" was a series of events that addressed both students and local stakeholders in tourism and culture management. Its goal was to provide participants with the appropriate knowledge and examples of best practice and tools to enable them to foster positive transformations through the extraction of value from culture, tourism and creativity. Illich's concept of tools for conviviality (1973) inspired the dialogues' settings. Conviviality - from the Latin convivium (banquet), derived from the verb convivere (living together) - inevitably involves sharing and - for Illich - became a symbol of people gathered for common and high purposes, including the re-building of the ways in which society and the economy work.

Intended to increase awareness and to inspire and foster networking, each dialogue was hosted in a place closely linked to its theme: the hosts were either already working with the theme of the dialogue, or the theme had the potential to transform the place itself. The locations included an exhibition space created within two disused tunnels and thus a symbol and catalyst of the culture-led transformation of a marginal urban area; a science museum born of the transformation of a traditional museum into a modern, eco-sustainable architectural structure; a cultural museum that is designing audience development and engagement projects aimed at greater social inclusion and the active involvement of a wider audience, including the museum's non-visitors. The dialogues leveraged the hybridization of 
management theory and practice (cases, guest speakers) with the performing arts and the use of different tools to engage people (students, practitioners). They became both educational and entertainment events: experts, practitioners, performing artists, and audiences participating in the dialogues were actively involved in interactions supported by video, images, storytelling, audience requests, and food sharing. The event settings also drew upon and enhanced people's memories, experiences, emotions, and conviviality.

\section{Emerging pedagogical pathways}

The cases discussed above provide examples of how universities in three different cultural contexts (Mexico, Canada, and Italy) are beginning to infuse their tourism education programs with a values-based perspective. This perspective is either directly or indirectly inspired by humanistic management elements (dignity, ethics, and legitimacy) (Pirson and Amann 2010) and/or by the Tourism Education Future Initiative's (TEFI 2010) values for tourism education (ethics, knowledge, stewardship, professionalism, mutuality). In these initial stages, the implementation of a values-based perspective is driven by individual faculty members who, themselves, strongly hold these values.

The interpretation and discussion of these teaching-learning experiences in the light of the Humanistic Tourism Education framework reveals new pathways in learning processes and outcomes and informs an intended capacity to build: what is taught (contents), why it is taught (capacity to build) and how it is taught (education strategies).

Contents. The ILOs of these international learning experiences in tourism management education cover a range of topics and levels of understanding, inspired fully or partially by humanistic management, humanistic tourism, and values-based principles including dignity. The building of relevant knowledge combines theoretical knowledge creation and practice in different ways. The Tourism and Hospitality seminar fully leveraged the new paradigms and notions that guide tourism towards better and more just outcomes and reinforced students' awareness of tourism impacts on people's individual, collective and cultural, economic, and labor spheres. Practical and contextualized knowledge was crucial to stimulate critical thinking and problem-solving about the living and working conditions of people in a particular destination, while also studying the best practices of the tourism organizations that are implementing humanistic tourism practices. The Field Studies in Hospitality and Tourism and Economy of Culture and Tourism courses have a narrower focus. The former largely focused on developing knowledge about the pillars of humanistic tourism in the specific context of community-based tourism. It addressed tourism development and sustainability issues in the socio-political context of a country, treated as a third place outside the classroom, and relied on multiple interactions with both the human actors and the non-human entities (Paget et al. 2010). The latter specifically addressed culture-based forms of tourism, including humanistic tourism, in different geographical and cultural contexts. Case study discussion in groups of (international) students, and guest speakers presenting engaging experiences, gave students the opportunity to acquire knowledge of, and think reflectively about, the novelty and advantage of installing a more values-based and humanistic set of norms to drive one's decision making and actions around culture-based tourism models.

Capacity to build. Building students' capacities and skills to become responsible managers is the fundamental aim of these international learning experiences in tourism 
management education. Flexible and hands-on pedagogical strategies give students an opportunity to exercise the responsible leadership required to answer the need for ethical, sustainable, and dignity-related strategies in tourism. In the Hospitality and Tourism seminar, students developed a booklet for tourism operators, suggesting how they could contribute to the 17 Sustainable Development Goals 2030; proposed ethical imperatives to guide destination marketing and management and suggested dignity-oriented tourism employment practices for hotels to help restore the dignity of indigenous people working in tourism destinations. Students also role-played tourism managers facing ethical dilemmas that required them to analyze alternative solutions, make decisions, and communicate these decisions to the relevant stakeholders; this exercise was well received by students who felt they were acting like real-life decision-makers. Similarly, following a week of experiencing tourism challenges in Jamaica, students were asked to make strategic recommendations for the development of community-based tourism. After studying the environment and interviewing various stakeholders, they identified barriers to development and could articulate sustainability-based recommendations for policymakers to benefit both local entrepreneurs and the Jamaican tourism product portfolio. In the Economy of Culture and Tourism course, students developed the capacity to recognize potential expressions of humanistic tourism in different geographical and cultural contexts, identify the factors to develop them fully (related to, for example, intangible cultural assets, tacit knowledge heritage, trust as collective and individual capital, leadership, innovative thinking, etc.) and critically discuss these factors in light of their diverse cultural backgrounds and value systems.

Education strategies. The education strategies that led to the building of these capacities clearly show that knowledge and understanding are co-created through active and interactive processes which are individual, social, emotional, and based on respect for the dignity of every person, whatever method, activity, and tool is used. The dialoguebased teaching methodology (Pirson 2017) manifests itself in different ways (e.g., interactive labs, in-class discussions, working groups, edutainment events, real-life cases, on-site visits, collective self-reflection discussions). It allows participants to actively contribute to the individual and common creation of knowledge coordinated by the lecturer who introduces the rules that ensure dignity within the interactions (Kostera and Pirson 2017): all participants have the same value, equal opportunities to express their ideas (using formal and informal language), in an equal, fair, impartial and non-judgmental atmosphere. Diversity is also evident in the dialogue-based teaching methodology which listens to the voices of people with different backgrounds, knowledge, expertise, and communication methods (practitioners, actors, storytellers, etc.), catalyzed by a combination of different tools (e.g., audio, video, case studies). Hybrid education in a third space (Bhabha 1994), out of the classroom (e.g., at cultural and tourism sites), allows students to encounter others (local communities, tourism and culture stakeholders, etc.) in different social and cultural contexts. These rich and immersive learning processes create a special atmosphere allowing participants (whatever their roles) to be intellectually, physically, and emotionally immersed in an experience and to play an active role, rather than merely entering a space/place where an experience is provided. This atmosphere allows human flourishing as people are encouraged to express their identity and creative potential fully and to develop their skills through high-quality human interactions that last after the experience itself is over. 


\section{Conclusion}

Only a few studies have addressed the importance of tourism higher education to instigate and support tourism to change (e.g., Andrades and Dimanche 2018; Mbarushimana et al. 2017); however, enhancing tourism education is essential to foster critical tourism practices. This paper contributes to bridging the gap between the need and the current capacity to provide tourism with alternative models and the leaders to implement them. It proposes to improve higher education in tourism management by using a novel and original perspective focused on human dignity and flourishing. The integration of humanistic management into tourism education and the adoption of a values-based approach provide an important opportunity to successfully address the increasing pressure to act as a responsible steward that tourism faces today.

This contribution presents an original Humanistic Tourism Education framework that cross-fertilizes recent advances in tourism education (Sheldon et al. 2008, TEFI 2010) with humanistic management education (Pirson and Amann 2010). It integrates dignity, ethics, and legitimacy with the values that should be the foundations for future tourism education initiatives, and it identifies the competencies that a responsible tourism manager must acquire.

Drawing on a selection of university learning experiences experimenting with valuesbased perspectives in tourism management education in different contexts, this study shows that new pathways consistent with our Humanistic Tourism Education framework are already in place. Explicitly or implicitly, these pedagogical approaches suggest ways of training ethical and responsible managers, aware of the social, cultural, and environmental challenges faced by their destinations.

Tourism education and humanistic management need to be integrated in order to create new contents which are both managerially relevant and useful, as well as to address traditional contents from a new perspective. Their blending can generate a synergistic force which empowers students and future managers to understand new challenges fully and thus inspires successful efforts to change. This solid yet multifaceted background equips students with the requisite knowledge to manage humanistically and responsibly; it instills an awareness of dignity, ethics (equality, diversity, inclusion, and respect), legitimacy, responsibility, sustainability in all relevant managerial functions such as strategy, operations/ logistics, marketing, finance, human resources, communication, and change management. Combining theoretical and practical knowledge is therefore crucial.

The crucial competencies that future responsible managers acquire are, in particular, the capacity to be agents of positive change and to impact society through their ability to respond appropriately and effectively to challenges. Such competencies require applying and adapting knowledge, taking risks (courage), going beyond self-referentiality (humility and curiosity), placing human beings at the center of every tourism organization, being patient and having fun. Some people have a natural aptitude for this, but such skills can also be trained and developed, particularly in young people.

The education strategies adopted to pursue the above outcomes must be multifaceted, delivered through dialogue-based methodologies and engaging tools and experienced both in the traditional learning context (classroom) and third places. These complex strategies allow the co-creation of knowledge by activating intrinsic assets (individual, social, emotional, etc.). Participants may not be fully aware of having these assets, or may not have experimented with them yet, or may even be scared or ashamed of experiencing them. The activation of diverse facets of our humanity allows us to reach out more effectively, interact 
with, and involve others, and create immediate opportunities, and (it is hoped) long-term effects.

The transition to a humanistic management education is full of promise but challenging. There are many limitations and barriers to overcome when transitioning towards a more values-based education in tourism. In the old paradigm, universities have established values and incentives and the consequent policies and routines; their staffing structure is traditional. Even when universities possess the places and spaces needed to adopt a humanistic tourism approach (the vision, resources, enlightened faculty members, staff, etc.), time, capability, and partnerships are nonetheless required to prepare, design, and implement such approaches, to innovate contents and education strategies and to engage colleagues, staff and industry stakeholders. Several challenges may be encountered when making changes: cross-cultural differences between students, especially in international contexts; a lack of student engagement with key module concepts and approaches; hesitancy about participating in class discussions and/or new learning formats. Finally, it is essential that lecturers be open to continuous training and self-questioning, only then can they build an understanding of diverse cultural backgrounds and value systems and recognize - and regularly revisit and interrogate - their own values.

\section{Limitations and future research}

Further studies are needed to overcome the limits of this exploratory contribution that deals with specific learning experiences in three universities and countries. Extensive case study analysis, on an international scale and covering a variety of universities and education or research areas, is needed to gain further insights into experimenting with valuesbased perspectives, which embed humanistic management, either directly or indirectly into tourism education programs. Best practices on both the supply and demand sides must be identified, in order to strengthen the connection between tourism education, managerial practice, and people's behaviors and beliefs. The advances made by the travel and tourism industry, tourism institutions, destination management organizations, and communities of practice embody these best practices. Companies that have already made significant progress towards a more respectful form of tourism include Intrepid Travel (https://www. intrepidtravel.com/ca/b-corp), a B Corporation; Greystone Bakery (https://www.greyston. org/); Responsible Travel (https://www.responsibletravel.com/); G Adventures (https:// www.gadventures.com/about-us/responsible-travel/); Explore! (https://www.explore.co. uk/about) or Fogo Island Inn (https://fogoislandinn.ca/). These businesses demonstrate that new directions can be taken, above all when visionary leaders focus on creating value for all their stakeholders.

Finally, longitudinal evaluation studies are needed to assess the paths taken by graduates who have been at the receiving end of humanistic tourism management education. Are they making a difference? Are they implementing ethical and respectful strategies in their businesses and destinations? Are these strategies being recognized as valuable and transformative by other players? Ultimately, the goal of a humanistic tourism management education is to enable future decision-makers to adopt a different perspective on the sector and their respective organizations. It will take time for the tourism industry to reinvent itself, but this study suggests that humanistic tourism management education can contribute to that effort.

Acknowledgments One of the authors would like to acknowledge the valuable support in co-designing and implementing innovative participative education formats received from Francesca Sorrentino, storyteller. 
Helpful comments and assistance from the journal editor, the guest editor and the anonymous reviewers in improving this paper are also gratefully acknowledged.

\section{Declaration}

Conflict of interest On behalf of all the authors, the corresponding author states that there is no conflict of interest.

\section{References}

Andrades, Lidia, and Frederic Dimanche. 2019. Destination competitiveness in Russia: Tourism professionals' skills and competences. International Journal of Contemporary Hospitality Management. https:// doi.org/10.1108/IJCHM-11-2017-0769.

Ateljevic, Irena. 2020. Transforming the (tourism) world for good and (re)generating the potential 'new normal'. Tourism Geographies. https://doi.org/10.1080/14616688.2020.1759134.

Becken, Susanne. 2013. A review of tourism and climate change as an evolving knowledge domain. Tourism Management Perspectives. https://doi.org/10.1016/j.tmp.2012.11.006.

Bhabha, Homi. 1994. The location of culture. London: Routledge.

Bianchi, Raoul V., and Frans de Man. 2021. Tourism, inclusive growth and decent work: A political economy critique. Journal of Sustainable Tourism. https://doi.org/10.1080/09669582.2020.1730862.

Biggs, John, and Catherine Tang. 2015. Constructive alignment: An outcomes-based approach to teaching anatomy. In Teaching anatomy, ed. Chan Lap Ki and Wojciech Pawlina. Cham: Springer. https://doi. org/10.1007/978-3-319-08930-04.

Boyle, Andrea, Erica Wilson, and Kay Dimmock. 2015. Transformative education and sustainable tourism: The influence of a lecturer's worldview. Journal of Teaching in Travel \& Tourism. https://doi.org/10. 1080/15313220.2015.1059303.

Brookfield, Stephen. 1987. Developing critical thinkers. Milton Keynes: Open University Press.

Brouder, Patrick. 2020. Reset redux: Possible evolutionary pathways towards the transformation of tourism in a COVID-19 World. Tourism Geographies. https://doi.org/10.1080/14616688.2020.1760928.

Burnes, Bernard. 2005. Complexity theories and organizational change. International Journal of Management Reviews. https://doi.org/10.1111/j.1468-2370.2005.00107.x.

Calgaro, Emma, Kate Lloyd, and Dale Dominey-Howes. 2014. From vulnerability to transformation: A framework for assessing the vulnerability and resilience of tourism destinations. Journal of Sustainable Tourism. https://doi.org/10.1080/09669582.2013.826229.

Camargo, Blanca A. 2011. Justice and fairness in tourism: A grounded theory study of cultural justice in Quintana Roo, Mexico (doctoral dissertation). Texas: Texas A\&M University.

Camargo, Blanca A., and Tazim Jamal. 2022. Dignity. In Encyclopedia of tourism management and marketing, ed. Dimitios Buhalis. Edward Elgar Publishing.

Camargo, Blanca A., and Mario Vázquez-Maguirre. 2021. Humanism, dignity and indigenous justice: The Mayan train megaproject, Mexico. Journal of Sustainable Tourism. https://doi.org/10.1080/09669582. 2020.1758707.

Cole, Stroma, and Nigel Morgan, eds. 2010. Tourism and inequality: Problems and prospects. Wallingford: CABI.

Della Lucia, Maria, and Ernestina Giudici. 2021a. Humanistic tourism: Values, norms and dignity. New York: Routledge.

Della Lucia, Maria, and Ernestina Giudici. 2021b. Humanistic management and sustainable tourism: Human, social and environmental challenges. New York: Routledge.

Della Lucia, Maria, Ernestina Giudici, and Frederic Dimanche. 2021. Lessons for shared value creation in tourism: The pandemic challenge. In Humanistic management and sustainable tourism: Human, social and environmental challenges, ed. Maria Della Lucia and Ernestina Giudici, 255-268. New York: Routledge.

Dodds, Rachel, Frederic Dimanche, and Michael Sadowski. 2018. Planning for growth in islands: The case of Cuba (Ch. 7). In Tourism management in warm-water island destinations, ed. Michelle McLeod and Roberto Croes, 95-107. Wallingford: CABI.

Dubois, Louis-Etienne, and Frederic Dimanche. 2021. The futures of entertainment dependent cities in a post-COVID world. Journal of Tourism Futures. https://doi.org/10.1108/JTF-11-2020-0208.

Dunkin, Michael J., and Bruce Biddle. 1974. The study of teaching. New York: Holt, Rinehart and Winston. 
Dwyer, Larry. 2018. Saluting while the ship sinks: The necessity for tourism paradigm change. Journal of Sustainable Tourism. https://doi.org/10.1080/09669582.2017.1308372.

Espiner, Stephen, and Susanne Becken. 2014. Tourist towns on the edge: Conceptualising vulnerability and resilience in a protected area tourism system. Journal of Sustainable Tourism. https://doi.org/ 10.1080/09669582.2013.855222.

Everingham, Phoebe, and Natasha Chassagne. 2020. Post COVID-19 ecological and social reset: Moving away from capitalist growth models towards tourism as Buen Vivir. Tourism Geographies. https://doi.org/10.1080/14616688.2020.1762119.

Fletcher, Robert. 2011. Sustaining tourism, sustaining capitalism? The tourism industry's role in global capitalist expansion. Tourism Geographies. https://doi.org/10.1080/14616688.2011.570372.

Giudici, Ernestina, Angela Dettori, and Federica Caboni. 2020. Challenges of humanistic management education in the digital era. In Virtuous cycles in humanistic management, contributions to management science, ed. Ricardo Aguado and Almudena Eizaguirre, 21-35. Cham: Springer Nature Switzerland.

Gössling, Stefan, and Michael C. Hall. 2006. Tourism and global environmental change. London: Taylor \& Francis.

Gössling, Stefan, Daniel Scott, and C. Michael Hall. 2020. Pandemics, tourism and global change: A rapid assessment of COVID-19. Journal of Sustainable Tourism. https://doi.org/10.1080/09669582. 2020.1758708.

Gretzel, Ulrike, Daniel Fesenmaier, Sandro Formica, and Joseph O'Leary. 2006. Searching for the future: Challenges faced by destination marketing organizations. Journal of Travel Research. https://doi.org/10.1177/0047287506291598.

Higgins-Desbiolles, Freya. 2006. More than an "Industry": The forgotten power of tourism as a social force. Tourism Management. https://doi.org/10.1016/j.tourman.2005.05.020.

Higgins-Desbiolles, Freya. 2020. COVID-19 and Tourism: Reclaiming tourism as a social Force? ATLAS Tourism and Leisure Review 2: 65-71.

Higgins-Desbiolles, Freya, Sandro Carnicelli, Chris Krolikowski, Gayathri Wijesinghe, and Karla Boluk. 2019. Degrowing tourism: Rethinking tourism. Journal of Sustainable Tourism. https://doi.org/10. 1080/09669582.2019.1601732.

Hockings, Marc, Nigel Dudley, Wendy Elliott, Mariana Napolitano Ferreira, Kathy MacKinnon, M.K.S. Pasha, and Angela Yang. 2020. Editorial Essay: COVID-19 and protected and conserved areas. Parks 26 (1): 7-24.

Illich, Ivan. 1973. Tools for conviviality. New York: Harper \& Row.

Jamal, Tazim. 2004. Virtue ethics and sustainable tourism pedagogy: Phronesis, principles and practice. Journal of Sustainable Tourism. https://doi.org/10.1080/09669580408667252.

Jamal, Tazim. 2021. Towards a new paradigm for regenerative tourism and just futures. The Good Tourism Blog. https://goodtourismblog.com/2021/06/towards-a-new-paradigm-for-regenerative-tourismand-just-futures/. Accessed 6 July 2021.

Kostera, Monika, and Michael Pirson. 2017. Dignity and organization. Basingstoke: MacMillan.

Lieberman, Paul B., and Leston L. Havens. 2002. Existential psychotherapy. Encyclopedia of Psychotherapy: 741-754.

Lo, Katherine. 2018. My experiential learning trip to Jamaica. https://global.blog.ryerson.ca/2018/10/ 12/my-experiential-learning-trip-to-jamaica/. Accessed 7 July 2021.

Manuel-Navarrete, David, and Michael Redclift. 2012. Spaces of consumerism and the consumption of space: Tourism and social exclusion in the "Mayan Riviera". In Consumer culture in Latin America, ed. John Sinclair and Ana Cristina Pertierra, 177-193. New York: Palgrave Macmillan.

Mbaiwa, Joseph E. 2016. Tourism development, dispossession and displacement of local communities in the Okavango Delta, Botswana. In Political ecology and tourism, ed. Senjay Nepal and Jarkko Saarinen, 217-230. London: Routledge.

Mbarushimana, Nelson, Elizabeth Role, and Vencie Allida. 2017. Competency-based curriculum in tourism and hospitality: A practical model for Rwanda. Journal of Research Innovation and Implications in Education 1 (3): 96-109.

McFarlane-Morris, Shenika. 2021. 'Come this close, but no closer!' Enclave tourism development and social change in Falmouth, Jamaica. Journal of Tourism and Cultural Change. https://doi.org/10. 1080/14766825.2019.1676253.

Melé, Domenec. 2003. The challenge of humanistic management. Journal of Business Ethics. https:// doi.org/10.1023/A:1023298710412.

Melé, Domenec. 2016. Understanding humanistic management. Humanistic Management Journal. https://doi.org/10.1007/s41463-016-0011-5. 
Niewiadomski, Piotr. 2020. COVID-19: From temporary de-globalisation to a rediscovery of tourism? Tourism Geographies. https://doi.org/10.1080/14616688.2020.1757749.

Nussbaum, Martha. 2011. Creating Capabilities. The human development approach. Cambridge: Belknap.

Paget, Elodie, Frederic Dimanche, and Jean-Pierre Mounet. 2010. A tourism innovation case: An actornetwork approach. Annals of Tourism Research. https://doi.org/10.1016/j.annals.2010.02.004.

Payne, Dinah, and Frederic Dimanche. 1996. Towards a code of conduct for the tourism industry: An ethics model. Journal of Business Ethics 15: 997-1007.

Pirson, Michael. 2017. Humanistic management: Protecting dignity and promoting well-being. Cambridge: Cambridge University Press.

Pirson, Michael, and Wolfgang Amann. 2010. Humanistic management education - concluding observations and suggestions. Fordham University Schools of Business Research. https://doi.org/10.2139/ ssrn. 1730383.

Pirson, Michael, and Shann Turnbull. 2011. Corporate governance, risk management, and the financial crisis: An information processing view. Corporate Governance: An International Review. https:// doi.org/10.1111/j.1467-8683.2011.00860.x.

Pirson, Michael, Mario Vázquez-Maguirre, Canan Corus, Erica Steckler, and Andrew Wicks. 2019. Dignity and the process of social innovation: Lessons from social entrepreneurship and transformative services for humanistic management. Humanistic Management Journal. https://doi.org/10.1007/ s41463-019-00071-9.

Prideaux, Bruce, Michelle Thompson, and Anja Pabel. 2020. Lessons from COVID-19 can prepare global tourism for the economic transformation needed to combat climate change. Tourism Geographies. https://doi.org/10.1080/14616688.2020.1762117.

Redwood, Loren. 2008. The rebuilding of a tourist industry: Immigrant labor exploitation in the postKatrina reconstruction of New Orleans. In Seeking higher ground, ed. Manning Marable and Kristen Clarke, 141-150. New York: Palgrave Macmillan.

Santonino, Michael D. 2021. The humanistic supervisor. In Humanistic tourism: Values, norms and dignity, ed. Maria Della Lucia and Ernestina Giudici, 166-190. New York: Routledge.

Sheldon, Pauline, Dan Fesenmaier, Karl Woeber, Cris Cooper, and Magda Antonioli. 2008. Tourism education futures 2010-2030: Building the capacity to lead. Journal of Teaching in Tourism \& Travel. https://doi.org/10.1080/15313220801909445.

Slocum, Susan L., Daniela Y. Dimitrov, and Kelley Webb. 2019. The impact of neoliberalism on higher education tourism programs: Meeting the 2030 sustainable development goals with the next generation. Tourism Management Perspectives. https://doi.org/10.1016/j.tmp.2019.01.004.

Spitzeck, Heiko. 2011. An integrated model of humanistic management. Journal of Business Ethics. https://doi.org/10.1007/s10551-011-0748-6.

Steel, Griet. 2012. Whose paradise? Itinerant street vendors' individual and collective practices of political agency in the tourist streets of Cusco, Peru. International Journal of Urban and Regional Research. https://doi.org/10.1111/j.1468-2427.2012.01153.x.

Swanson, Diane L. 2004. The buck stops here: Why universities must reclaim business ethics education. Journal of Academic Ethics. https://doi.org/10.1023/B:JAET.0000039007.06014.24.

Tourism Education Futures Initiative-TEFI 2010. A values-based framework for tourism education: Building the capacity to lead. White paper. https://docs.google.com/viewer?a=v\&pid=sites\&srcid= ZGVmYXVsdGRvbWFpbnx0b3VyaXNtZWR1Y2F0aW9uZnV0dXJlc3xneDo2OTZhMTNjN jVjN2NmYjVj. Accessed 6 July 2021.

Tribe, John. 2002. The philosophic practitioner. Annals of Tourism Research. https://doi.org/10.1016/ S0160-7383(01)00038-X.

Tribe, John. 2008. Tourism: A critical business. Journal of Travel Research. https://doi.org/10.1177/ 0047287507304051.

UNWTO. 2020. Responsible tourism: The key to building back a better industry. https://www.unwto. org/covid-19-oneplanet-responsible-recovery-initiatives/responsible-tourism-the-key-to-buildingback-a-better-industry. Accessed 7 July 2021.

Waldron, Jeremy. 2013. The paradoxes of dignity - about Michael Rosen, dignity: Its history and meaning (Harvard University Press, 2012). European Journal of Sociology. https://doi.org/10.1017/ S0003975613000404.

Winchenbach, Anke, Paul Hanna, and Graham Miller. 2019. Rethinking decent work: The value of dignity in tourism employment. Journal of Sustainable Tourism. https://doi.org/10.1080/09669582. 2019.1566346. 
World Travel and Tourism Council (2021). Travel and tourism global economic impact 2021.Global economic impact \& trends 2021. https://wttc.org/Portals/0/Documents/Reports/2021/Global\%20Eco nomic\%20Impact\%20and\%20Trends\%202021.pdf. Accessed 23 October 2021.

Wright, Kelly-Ann, and Frederic Dimanche. Forthcoming. Canadian immigration policies: Implications for discrimination and biases in tourism employment. In Inclusion in tourism: Understanding institutional discrimination and bias, ed. Sue Slocum. London: Routledge.

Yin, Robert K. 2014. Case study research: Design and methods. Thousand Oaks: Sage Publications.

Publisher's Note Springer Nature remains neutral with regard to jurisdictional claims in published maps and institutional affiliations.

\section{Authors and Affiliations}

\section{Maria Della Lucia ${ }^{1}$ (D) - Frédéric Dimanche ${ }^{2}$ - Ernestina Giudici ${ }^{3}$. Blanca Alejandra Camargo ${ }^{4} \cdot$ Anke Winchenbach $^{5}$}

Frédéric Dimanche

fdimanche@ ryerson.ca

Ernestina Giudici

ernestgiu@gmail.com

Blanca Alejandra Camargo

blanca.camargo@udem.edu

Anke Winchenbach

anke.winchenbach@surrey.ac.uk

1 Department of Economics and Management, University of Trento, Trento, Italy

2 Ted Rogers School of Hospitality and Tourism Management, Ryerson University, Toronto, Canada

3 Department of Economic and Business Sciences, University of Cagliari, Cagliari, Italy

4 Business School, Universidad de Monterrey, Monterrey, Mexico

5 School of Hospitality and Tourism Management, University of Surrey, Surrey, UK 